\title{
Utilization of Recycled Polypropylene for Production of Eco-Composites
}

\author{
Vineta Srebrenkoska ${ }^{1}$, Gordana Bogoeva Gaceva ${ }^{2}$, Maurizio Avella ${ }^{3}$, Maria \\ Emanuela Ericco ${ }^{3}$, and Gennaro Gentile ${ }^{3}$ \\ ${ }^{1}$ Faculty of Technology, Goce Delčev University, "Krste Misirkov", Štip, Republic of Macedonia \\ ${ }^{2}$ Faculty of Technology and Metallurgy, Sts. Cyril \& Methodius University, Skopje, \\ Republic of Macedonia \\ ${ }^{3}$ Institute of Chemistry and Technology on Polymers - ICTP-CNR, Pozzuoli, Napoli, Italy
}

\begin{abstract}
Renewable raw materials and recyclable thermoplastic polymers provide attractive eco-friendly quality as well as environmental sustainability to the resulting natural fiber reinforced composites. We studied the possibility of using the recycled polypropylene (PP) for production of composites based on kenaf fibers (KF) and rice hulls (RH) as reinforcements. Polypropylene/rice-hulls (PPI RH/CA) and polypropylene/kenaf (PP/K/CA) composites with $30 \%$ fiber (filler) content and appropriate compatibilizing agent (CA) - a maleic anhydride grafted PP (MAPP), have been prepared by two steps procedure: melt mixing and compression molding. Flexural strength and thermal stability of the composites with recycled PP were similar to those with neat $P P$. The composites reinforced with kenaf fibers have shown better properties than those based on rice hulls. The flexural strength of the composite sample with recycled $\mathrm{PP}$ is $51.3 \mathrm{MPa}$ in comparison with $51.1 \mathrm{MPa}$ for the composite with neat PP. Degradation temperatures of neat and composite with recycled $P P$ at residual weight $90 \%$ are $344.4^{\circ} \mathrm{C}$ and $343.5^{\circ} \mathrm{C}$, respectively. The results obtained report the possibility of utilization of recycled $P P$ for the production of natural reinforcements based composites with good mechanical characteristics for using as construction building materials in housing systems.
\end{abstract}

Keywords Compression molding; Eco-composites; Kenaf fibers; Polypropylene; Rice hulls

\section{INTRODUCTION}

New and stronger environmental policies have forced some industries to look for new eco-materials that will be able to substitute traditional composites reinforced with glass or carbon fibres ${ }^{[1]}$. For auto markets, it becomes important to improve recyclability of newly produced vehicles. The European Commision has proposed the European Guideline 2000/53/EG that sets a goal of improving automotive recyclability, $85 \%$ by weight of a vehicle being recyclable by 2005 and $95 \%$ by $2015^{[2]}$.

Address correspondence to Vineta Srebrenkoska, Faculty of Technology, Goce Delčev University, "Krste Misirkov" b.b. P.O. Box 201, 2000 Stip, Republic of Macedonia. E-mail: vineta. srebrenkoska@ugd.edu.mk
Natural fibers (NF) reinforced materials offer target environmental advantages such as reduced dependence on non-renewable energy/material sources, lower pollutant and greenhouse emission ${ }^{[3,4]}$. Processing of these composites offer easy and cost-effective processes, so the market for eco-composites seems to be promising and realizable for double-digit growth in the near future ${ }^{[5-7]}$. Natural lignocellulosic fibers (flax, jute, hemp, etc.) represent an environmentally friendly alternative to conventional reinforcing fibers (glass, carbon) ${ }^{[8]}$. Depending of their performance, when they are included in the polymer matrix, lignocellulosic fibers can be classified into three categories: (1) wood flour particulates, which increase the tensile and flexural modulus of the composites, (2) fibers of higher aspect ratio that contribute to improving the composites modulus and strength when suitable additives are used to regulate the stress transfer between the matrix and the fibers, and (3) long, natural fibers with the highest efficiency amongst the lignocellulosic reinforcements. The most efficient natural fibers have been considered those that have a high cellulose content coupled with a low microfibril angle, resulting in high filament mechanical properties.

Among eco-compatible polymer composites, special attention has been given to polypropylene composites, due to their added advantage of recycability ${ }^{[9]}$. As an oil-based product, PP could not be classified as a biodegradable polymer, but by introducing thermosensitive catalysts to increase the degradability, PP takes an important place in eco-composite materials. For example, Mohanty et al. have demonstrated that the NF reinforced PP composites have potential to replace glass-PP composites ${ }^{[10]}$. It has also been reported that PP can be modified by maleic anhydride, as an effective adhesion promoter ${ }^{[11]}$.

Significant research efforts have been also spent on eco composites based on recyclable polymers with NFs. Curently, PP is used for great number of recyclable eco-composites. Visteon and Technilin developed their 
own flax/PP material R-Flax ${ }^{\circledR}$, based on a low cost fiber. Taking into account very high specifications from Opel, which include critical safety requirements, R-Flax can be used for interior items (door panels), where its aesthetic qualities can even add to its consumer appeal. Tech-Wood International from the Netherlands announced its TechWood $^{\circledR}$ eco-composite, aimed for construction elements ${ }^{[12]}$. Tech-Wood ${ }^{\mathbb{R}}$ eco-composite material contains $70 \%$ pinewood fibers and 30\% compatibilized PP.

Yang et al. have studied the possibility of using lignocellulosic rice-husk flour (RHF) as the reinforcing filler (10$40 \mathrm{wt} \%$ ) in polyolefine composites ${ }^{[1,13]}$. The results of tensile tests performed have shown that tensile strength of the composites slightly decreased as the filler load increased. Applying the method used in the wood-based panel industry, composite insulation boards were produced with rice straw ${ }^{[14]}$. Composite boards with specific gravity of 0.8 have slightly better bending modulus than wood particle board (as a control board) at a rice straw content of $10 \mathrm{wt} \%$, and show no differences from the control boards at a $20 \mathrm{wt} \%$ rice straw level. Toro et al. ${ }^{[15]}$ have studied the compatibilizing effect of polypropylene grafted with monomethyl itaconate (PP-g-MMI) in PP/rice-husk composites. It was shown that in the presence of compatibilizer, the tensile modulus and water absorption of the composite were improved.

The purpose of the work reported in this study was to investigate the properties of PP composites reinforced with kenaf fiber or rice hulls, compounded with recycled PP matrix and a coupling agent by reactive blending, and consequent compression molding. The work is a part of an ECO-PCCM project ${ }^{[16]}$, in which eco-composites based on polypropylene (PP), poly (L-lactic acid) (PLA) and poly (hydroxybutyrate-co-hydroxyvalerate) (PHBV), reinforced with different natural fibers and fillers, were prepared and investigated in order to create new eco-compatible construction panels and elements for eco-houses.

\section{EXPERIMENTAL}

\section{Materials}

Isotactic PP, Moplen X30S $\left(M_{n}=4.69 \times 10^{4} \mathrm{~g} \mathrm{~mol}^{-1}\right.$, $M_{w}=3.5 \times 10^{5} \mathrm{~g} \mathrm{~mol}^{-1}$ and $\left.M_{z}=2.06 \times 10^{6} \mathrm{~g} \mathrm{~mol}^{-1}\right)$, were kindly supplied by basell Polyolefins (Ferrara, Italy). Rice-hulls from agricultural waste were kindly supplied by Rice Institute from Kocani, Macedonia. Kenaf fibers, average length of $5.1 \mathrm{~mm}$ and average diameter $21 \mu \mathrm{m}$, were kindly supplied by Kenaf Eco Fibers Italia S.p.A. (Guastall-Italy). Before mixing, kenaf fibers $(\mathrm{K})$ and the rice hulls $(\mathrm{RH})$ were vacuum-dried for $24 \mathrm{~h}$ to adjust the moisture content to $1-2 \mathrm{wt} \%$.

Maleic anhydride - grafted PP (MAPP) KA 805 (Basell polyolefins, Ferrara, Italy), was used as a coupling agent (CA).

\section{Compounding of Composite Materials}

First, the PP matrix was recycled one and two times (PPx1 and PPx2) by an extrusion procedure using a twinscrew extruder. The obtained recycled polymers were cut into granules to perform the sheets. In the experiments with the recycled polymer, PP was used without any additional additives. The preparation of the composites was preformed by melt mixing, in a Haake Rheocord 9000 batch mixer (New Jersey, USA). First the polymer (PP) and the coupling agent (MAPP) were mixed for $3 \mathrm{~min}$ at $185^{\circ} \mathrm{C}$; then $30 \mathrm{wt} \%$ of fillers/fibers were added and the mixing proceeded for further $10 \mathrm{~min}$ at the same temperature. The mixing speed was progressively increased during mixing, up to $64 \mathrm{rpm}$ ( 3 min with a mixing speed of $8 \mathrm{rpm}$, then $4 \mathrm{~min}$ at $38 \mathrm{rpm}$ and finally $3 \mathrm{~min}$ at $64 \mathrm{rpm}$ ). Then the composites obtained were cut into granules to perform the sheets. In order to investigate the possibility of utilization of the recycled polypropylene for the production of new eco-composite materials with appropriate mechanical and thermal properties, several composites have been prepared, as shown in Table 1.

\section{Compression Molding}

The samples for mechanical analysis were fabricated by compression moulding. The pellets obtained after each mixing process were put in molding frames $(10 \times 10 \times$ $0.35 \mathrm{~cm}^{3}$ ) and compression molded at $\mathrm{T}=185^{\circ} \mathrm{C}$ for 10 minutes, with progressively increasing pressure from 50 to $150 \mathrm{~Pa}$. Finally, the press was cooled using a cold water

TABLE 1

Codes of the composites produced with recycled PP matrix

\begin{tabular}{|c|c|c|c|c|c|c|}
\hline \multirow[b]{2}{*}{ Code } & \multicolumn{2}{|c|}{ Matrix } & \multicolumn{2}{|c|}{ Fiber/filler } & \multicolumn{2}{|c|}{ Coupling agent (CA) } \\
\hline & Type & Content $(w t \%)$ & Type & Content $\left(w t^{\%} \%\right)$ & Type & Content $\left(\mathrm{wt}^{\mathrm{t}} \%\right)$ \\
\hline $\mathrm{PP} / \mathrm{RH} / \mathrm{CA}$ & PP & 60 & Rice hulls & 30 & MAPP & 10 \\
\hline $\mathrm{PPx} 1 / \mathrm{RH} / \mathrm{CA}$ & PP recycled once & & & & & \\
\hline $\mathrm{PPx} 2 / \mathrm{RH} / \mathrm{CA}$ & PP recycled twice & & & & & \\
\hline $\mathrm{PP} / \mathrm{K} / \mathrm{CA}$ & PP & 60 & Kenaf & 30 & MAPP & 10 \\
\hline $\mathrm{PPx} 1 / \mathrm{K} / \mathrm{CA}$ & PP recycled once & & & & & \\
\hline
\end{tabular}


flow. Sheets with a thickness of about $3.5 \mathrm{~mm}$ were obtained for further analyses.

\section{Methods}

Flexural tests were performed according to ASTM D 638-99 standard on a universal Instron machine (model 4301). The tests were performed at a crosshead speed of

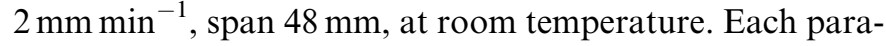
meter evaluated represents the average of 6 specimens. The obtained composites have been characterized by flexural tests, thermogravimetry (TGA) and scanning electron microscopy (SEM). The flexural testing was performed by using unnotched samples. Each result obtained represents the average of 6 samples.

The thermal stability of the samples was measured using a Perkin Elmer Pyris Diamond TGA instrument. About $10 \mathrm{mg}$ of each sample was heated from 50 to $600^{\circ} \mathrm{C}$ at a heating rate of $20^{\circ} \mathrm{C} \mathrm{min}^{-1}$ under nitrogen flow $(25 \mathrm{ml}$ $\min ^{-1}$ ). Morphological analysis was performed using a JEOL SEM instrument, on cryogenically fractured surfaces of composite samples. Before observation, the specimens were metalized with a gold/palladium coating.

\section{RESULTS AND DISCUSSION Mechanical Analysis}

The flexural properties of the recycled PP are shown in Table 2. The flexural strength of the composites produced from the neat and the recycled PP (PPx1 and PPx2) are similar, although the modulus of PPx1 and PPx2-based composites are higher than for the neat-PPbased composites.

As shown in Figure 1 the flexural strengths for PP are decreased for about 5\% with increasing of the number of recycles, but the flexural modulus are increased for about $25 \%$. PP-based composites were prepared by appropriate in situ reactive compatibilization. This preparation strategy includes the addition of a small amount of MAPP (reactive coupling agent) to the composite components. This coupling agent is constituted of PP segments such as the polymer matrix and of maleic anhydride groups grafted onto PP segments, which becomes reactive with respect to hydroxyl and maleic anhydride groups, generated during mixing, are responsible for grafted species formed in situ that can act as an effective compatibilizer for the PP/ natural reinforcement composite.

TABLE 2

Results of flexural test of neat and recycled PP

\begin{tabular}{lcc}
\hline Sample & Stress at peak $(\mathrm{MPa})$ & Modulus $(\mathrm{GPa})$ \\
\hline PP neat & $51.5 \pm 5.5$ & $1.08 \pm 0.12$ \\
PPx1 & $52.8 \pm 2.1$ & $1.31 \pm 0.06$ \\
PPx2 & $49.5 \pm 2.9$ & $1.34 \pm 0.11$ \\
\hline
\end{tabular}

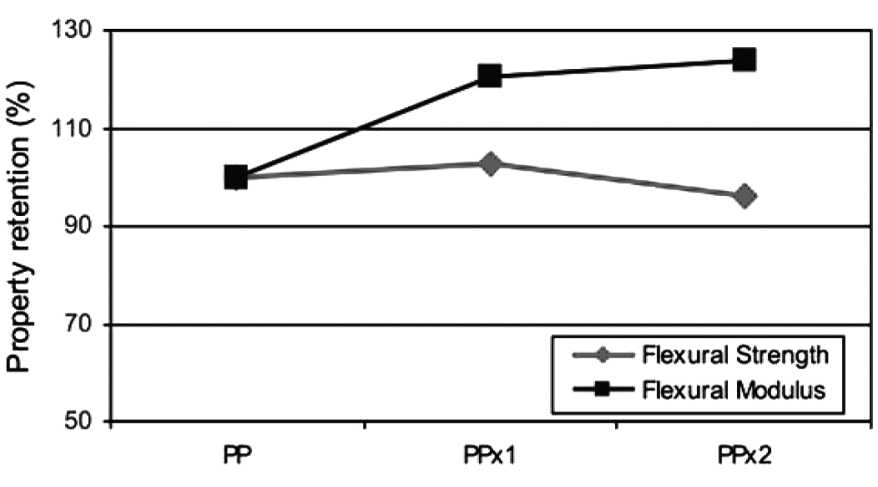

FIG. 1. Influence of the recycling process on flexural strength and flexural modulus of PP matrix.

In order to evaluate the behavior of the composites made with recycled matrices, in terms of their mechanical and thermal properties, the matrices were extruded two times as reported in the experimental section. The flexural properties of the kenaf and rice hulls composites with neat and recycled matrices are summarized in Table 3. Generally, the kenaf-composites have better mechanical properties than the rice hulls ones, due to the reinforcing effect of the fibers having much a higher aspect ratio.

As shown in Figure 2, which presents the property retention of the composites based on neat PP, PPx1 and PPx2, the flexural properties for PP recycled-based composites were held close to the flexural properties for composite based on neat PP. Serizawa et al. ${ }^{[17]}$ has studied the recycling properties of PLA/kenaf composite. The physical properties and molecular weight were held close to $90 \%$ of that of the initial PLA/kenaf composites. The reason for the decrease in the physical properties was mainly the decline in the molecular weight of PLA and the kenaf fiber's length caused by repeated kneading.

The results for the mechanical properties of ecocomposites based on PP reinforced with different NFs obtained in the framework of ECO-PCCM project ${ }^{[13,16]}$ are presented in Figure 2. The increased rice hulls content has resulted in a higher flexural modulus, $E$, $(E P P /$ $\mathrm{RH}(80 / 20)=1342 \mathrm{MPa}, \quad E \mathrm{PP} / \mathrm{RH}(70 / 30)=1451 \mathrm{MPa})$;

TABLE 3

The results of flexural test of composites with neat and recycled $\mathrm{PP}$

\begin{tabular}{lcc}
\hline Sample & Stress at peak (MPa) & Modulus (GPa) \\
\hline PP/RH/CA & $42.6 \pm 3.4$ & $1.94 \pm 0.082$ \\
PPx1/RH/CA & $42.2 \pm 1.2$ & $1.82 \pm 0.041$ \\
PPx2/RH/CA & $39.6 \pm 4.6$ & $1.84 \pm 0.063$ \\
PP/K/CA & $51.3 \pm 4.8$ & $2.11 \pm 0.068$ \\
PPx1/K/CA & $51.1 \pm 3.0$ & $2.35 \pm 0.204$ \\
\hline
\end{tabular}




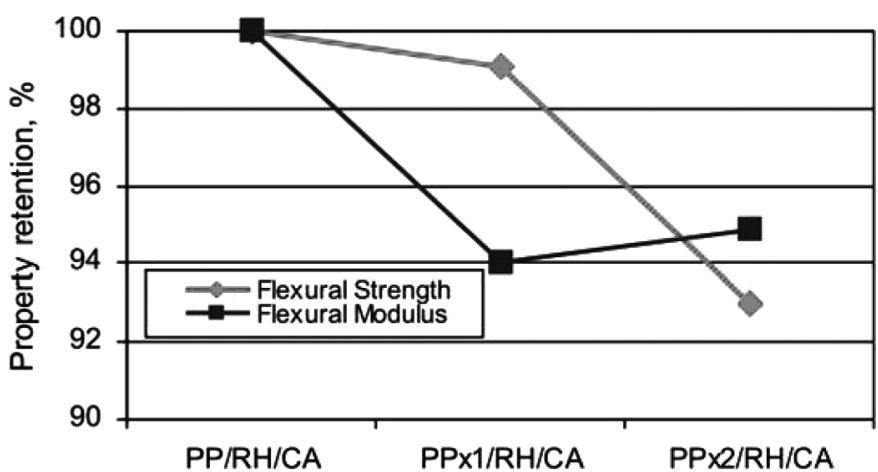

(a)

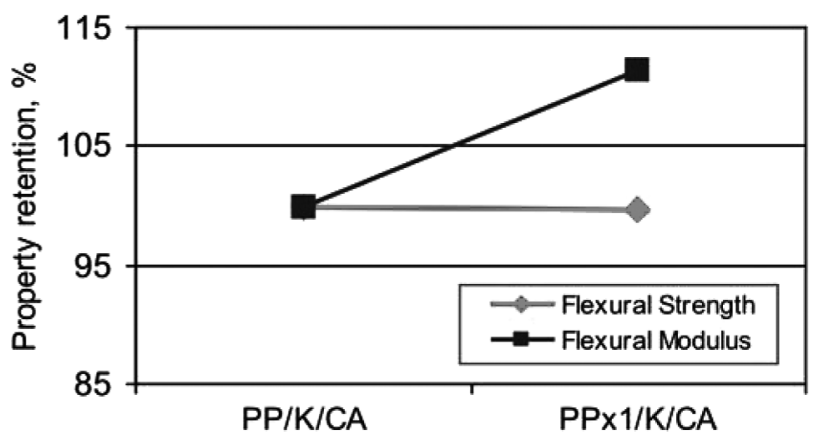

(b)

FIG. 2. Influence of the recycled PP on flexural strength and flexural modulus of (a) $\mathrm{PP} / \mathrm{RH}$ composites and (b) $\mathrm{PP} / \mathrm{K}$ composites.

however, flexural strength was reduced for about $20 \%$. Obviously, at higher rice hulls content, the interfacial area between the filler and the polymer also increased, which reduced the interfacial bonding between the rice hulls (hydrophilic) and polypropylene (hydrophobic matrix). For irregular shape reinforcements, the strength of the composites decreases, due to inability of reinforcement to support stress transfer from the polymer matrix ${ }^{[18]}$. Mechanical behavior of the composites, reinforced with kenaf fibers or rice hulls, produced from the recycled PP, has been improved by using the compatibilizing agent and by increasing its amount from $5 \%$ to $10 \%$, as can be seen from Figure 3.

Since the industrial manufacturing of the composites proceeds mainly in a nonisothermal regime, analysis of the crystallization parameters and crystallization behavior of the polypropylene composites is important from a practical point of view. Generally speaking, for composites based on semicrystalline polymers, the crystallinity is an important factor that determines the stiffness and fracture behavior of the crystallized polymer matrix ${ }^{[19]}$. The crystallinity depends upon processing parameters, e.g., $T_{c}$, cooling rate, nucleation density and annealing time ${ }^{[20]}$. It should be mentioned that, in our previous paper ${ }^{[21]}$, it was reported that the addition of rice hulls or kenaf fibers to PP resulted

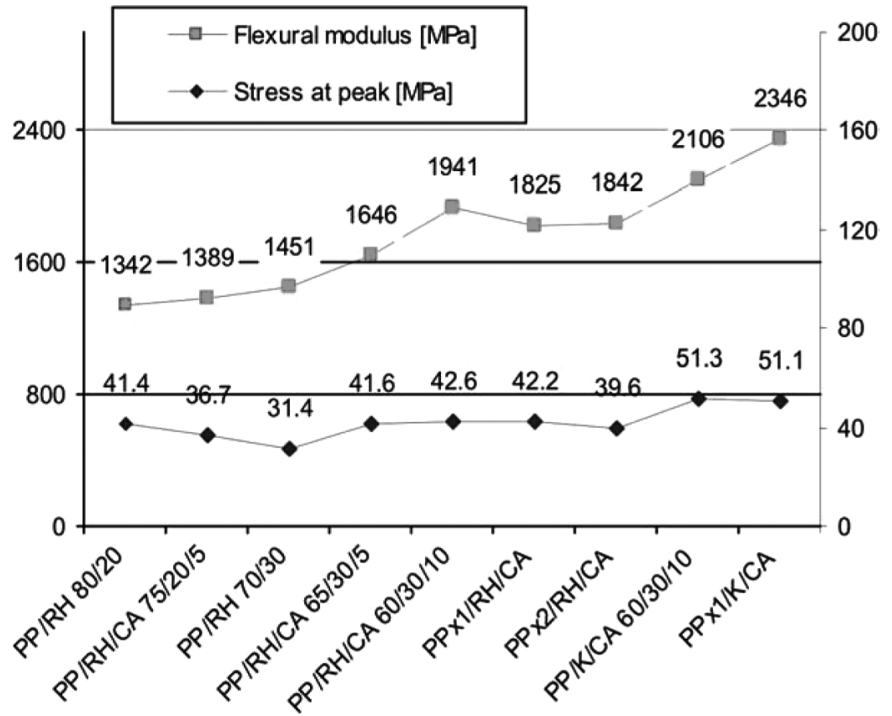

FIG. 3. Flexural data for neat-PP-based composites with different amount of RH, kenaf and CA, compared to $\mathrm{PP}$ composites produced from recycled PP.

in an increased crystallization temperature and accelerated crystallization process, due to the "nucleating" effect of the filler ${ }^{[20]}$. This behavior could advantageously affect the processing of the composites.

\section{TGA Results}

TGA curves and derivate thermograms (DTG) for PP neat, PPx1, PPx2 and for kenaf fibers and rice hulls are shown in Figures 4 and 5. Thermal degradation of PP and PPx 1, PPx 2 showed a single stage process and occurred at $443.9^{\circ} \mathrm{C}, 432.9^{\circ} \mathrm{C}$ and $422^{\circ} \mathrm{C}$, respectively, and the curves have the same appearance. The weight loss step of PP occurs slowly below $430^{\circ} \mathrm{C}$, but the weight loss rate strongly increases after $430^{\circ} \mathrm{C}$ and the degradation process is completed at $560^{\circ} \mathrm{C}$. The thermal stability of the recycled PPx 1 and PPx2 are almost without differences but is slightly lower compared to the neat PP. In kenaf fibers and rice hulls composites, two-stage mass loss process was observed. The first stage in the temperature range from $200^{\circ} \mathrm{C}$ to $300^{\circ} \mathrm{C}$ is characteristic of low molecular weight components, such as hemicellulose and cellulose and the second one near $350^{\circ} \mathrm{C}$ corresponds to the thermal degradation of lignin.

The lignocellulosic materials are chemically active and decompose thermochemically between $150^{\circ} \mathrm{C}$ and $500^{\circ} \mathrm{C}$ : hemicellulose, mainly between 150 and $350^{\circ} \mathrm{C}$, cellulose between 275 and $350^{\circ} \mathrm{C}$, and lignin between 250 and $500^{\circ} \mathrm{C}^{[22]}$. The rest at about $550^{\circ} \mathrm{C}$ in the rice hulls, which is determined by TGA, corresponded to the amount of silica. Ash in the rice hulls (12\%) is mainly constituted as silica (ca $96 \mathrm{wt} \%$ ), and the amount and distribution of silica 

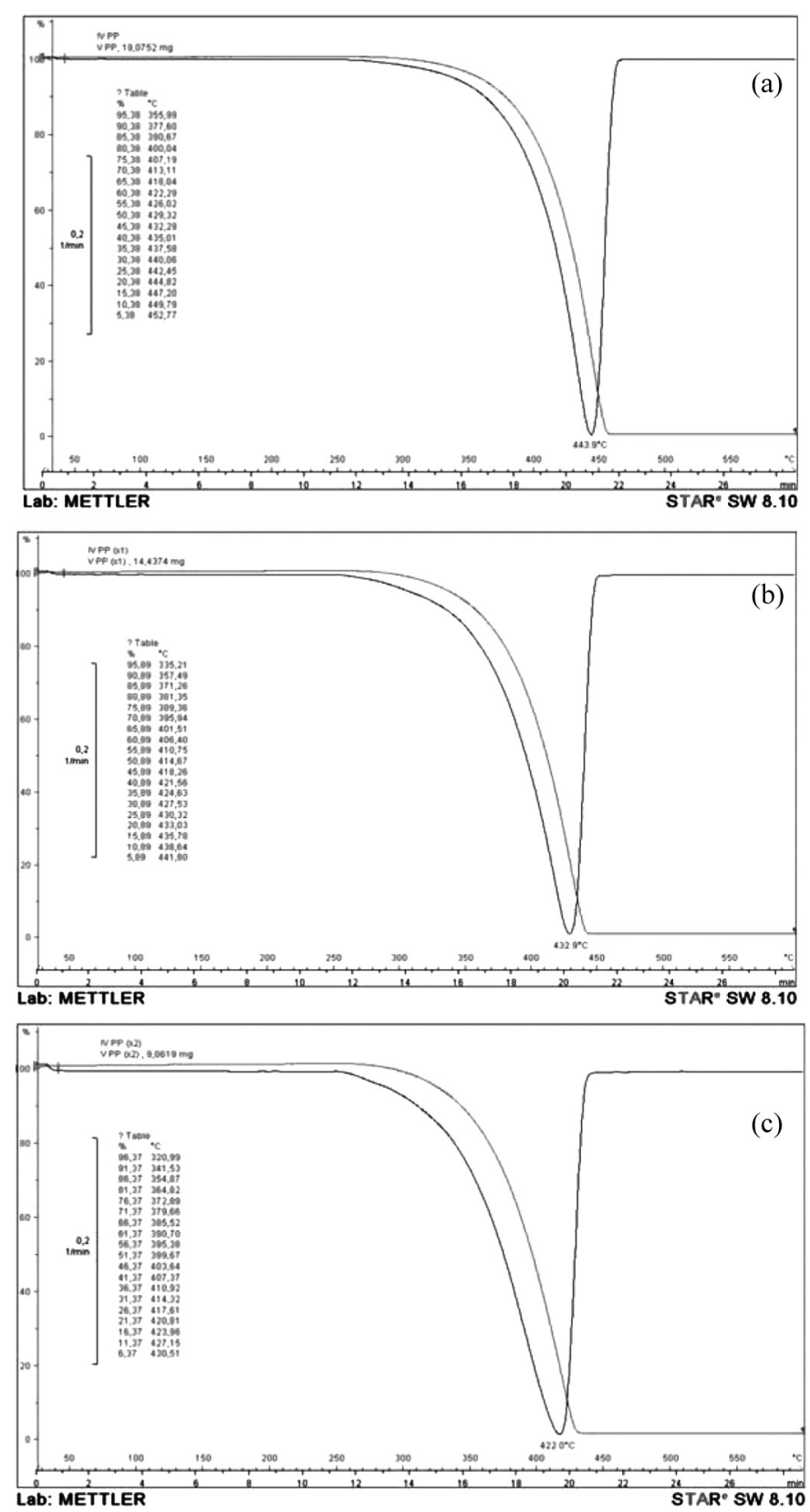

FIG. 4. Weight loss and weight loss rate curves of (a) PP, (b) PPx1 and (c) PPx2.

in the rice hulls is likely to be an important factor in determining the properties of the composite products ${ }^{[22]}$.

In PP-recycled based composites, the utilization of the recycled matrix has only slightly affected the thermal degradation temperature (Fig. 6). In the case of PP/K composites, a two-stage weight loss process was observed. The first stage, occurring in the temperature range $350-400^{\circ} \mathrm{C}$, is correlated with the degradation of low molecular weight components, such as hemicelluloses and cellulose, corresponding to thermal degradation of kenaf. Table 5. shows
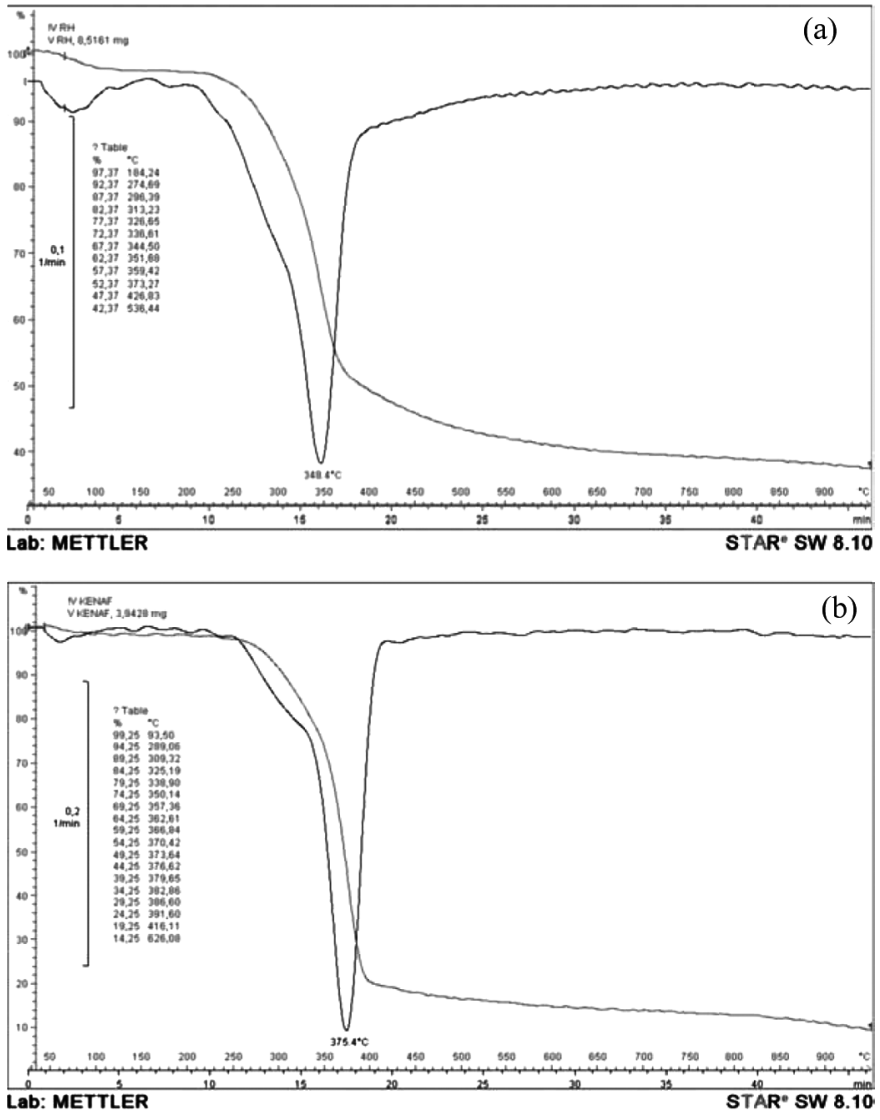

FIG. 5. Weight loss and weight loss rate curves of (a) rice hulls and (b) kenaf fibers.

a very slight increase of the degradation temperature for $\mathrm{PPx} 1 / \mathrm{K}$ composite after recycling of the matrix. In the case of $\mathrm{PP} / \mathrm{RH}$ composites, PPx $1 / \mathrm{RH}$ composite shows a decrease of degradation temperature (about $40^{\circ} \mathrm{C}$ ) after the first recycling of the matrix and $\mathrm{PPx} 2 / \mathrm{RH}$ composite shows the same degradation temperature as neat compost.

To explain these results, equally probable different phenomena and/or their combination occurring during recycling of the matrices must be taken into account. In fact, either partial degradation of PP occurs, or the extent of the reaction between maleic groups of the compatibilizer and hydroxyl groups of cellulose is increased. In this latter case, a better interfacial adhesion could be obtained as a result of the recycling process of the matrices, and this phenomenon could explain the improvement of the thermal stability and the interesting mechanical response of recycled matrices-based composites ${ }^{[23-25]}$.

\section{Morphological Analysis}

Figures 7 and 8 show SEM micrographs of cryogenically fractured samples of neat and composites with recycled matrices, thus allowing the evaluation not only of the filler 

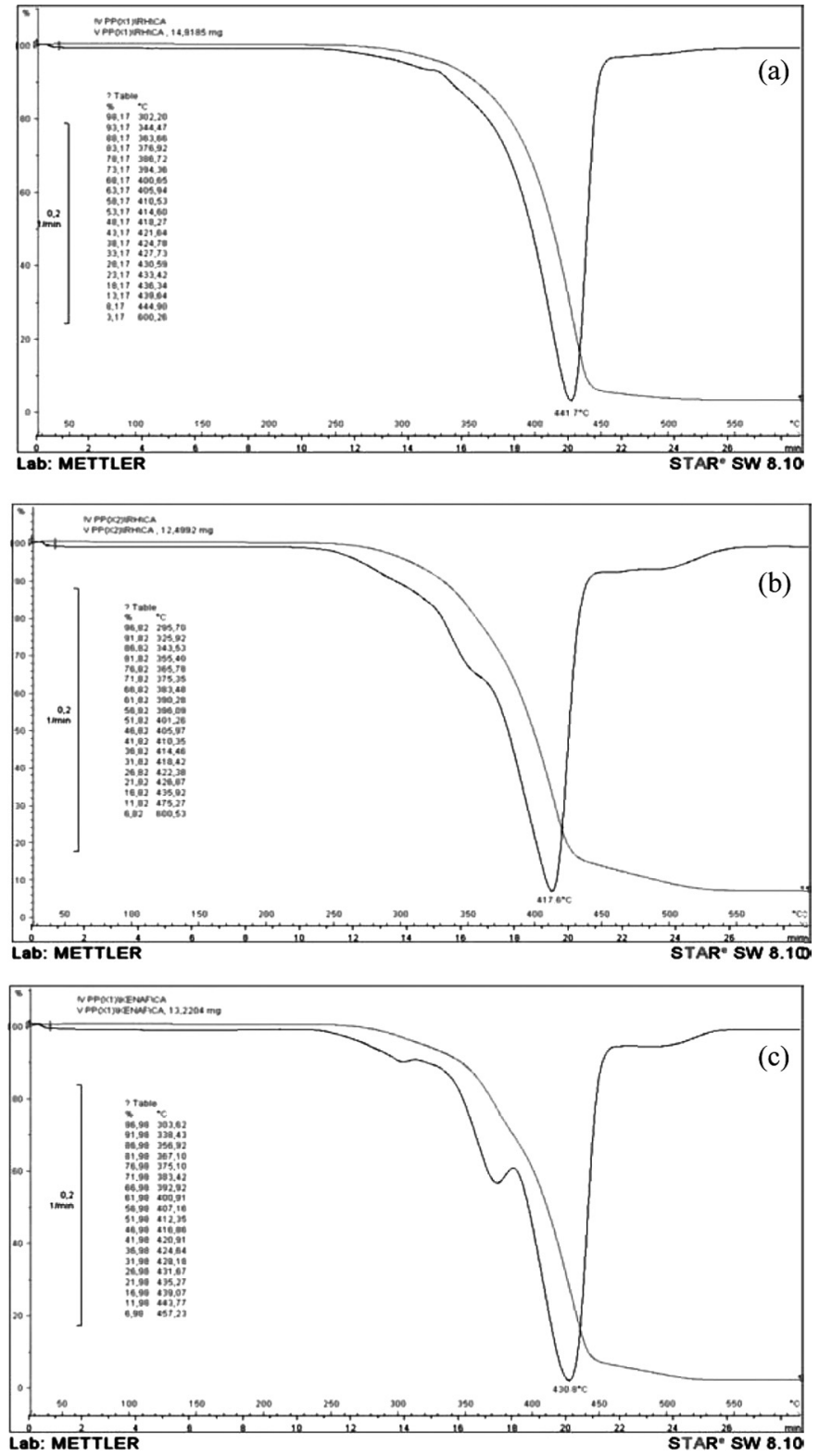

FIG. 6. Weight loss and weight loss rate curves of (a) PPx1/RH/CA, (b) $\mathrm{PPx} 2 / \mathrm{RH} / \mathrm{CA}$ and (c) PPx $1 / \mathrm{K} / \mathrm{CA}$.

TABLE 4

Degradation temperature of neat and recycled PP determined by TGA at residual weight $90 \%\left(T d_{90}\right)$, $50 \%\left(T d_{50}\right)$ and $10 \%\left(T d_{10}\right)$

\begin{tabular}{lccc}
\hline Sample & $T d_{90}\left({ }^{\circ} \mathrm{C}\right)$ & $T d_{50}\left({ }^{\circ} \mathrm{C}\right)$ & $T d_{10}\left({ }^{\circ} \mathrm{C}\right)$ \\
\hline PP neat & 377.6 & 429.3 & 449.8 \\
PPx1 & 357.5 & 414.7 & 438.6 \\
PPx2 & 354.9 & 403.6 & 427.2 \\
\hline
\end{tabular}

TABLE 5

Degradation temperature of neat and composites with recycled matrices determined by TGA at residual weight $90 \%\left(T d_{90}\right), 50 \%\left(T d_{50}\right)$ and $10 \%\left(T d_{10}\right)$

\begin{tabular}{lccc}
\hline Sample & $T d_{90}\left({ }^{\circ} \mathrm{C}\right)$ & $T d_{50}\left({ }^{\circ} \mathrm{C}\right)$ & $T d_{10}\left({ }^{\circ} \mathrm{C}\right)$ \\
\hline PP/RH/CA & 344.4 & 411.2 & 452.2 \\
PPx1/RH/CA & 309.1 & 385.2 & 458.8 \\
PPx2/RH/CA & 343.5 & 406.0 & 475.3 \\
PP/K/CA & 356.8 & 408.9 & 442.0 \\
PPx1/K/CA & 356.9 & 412.3 & 443.8 \\
\hline
\end{tabular}
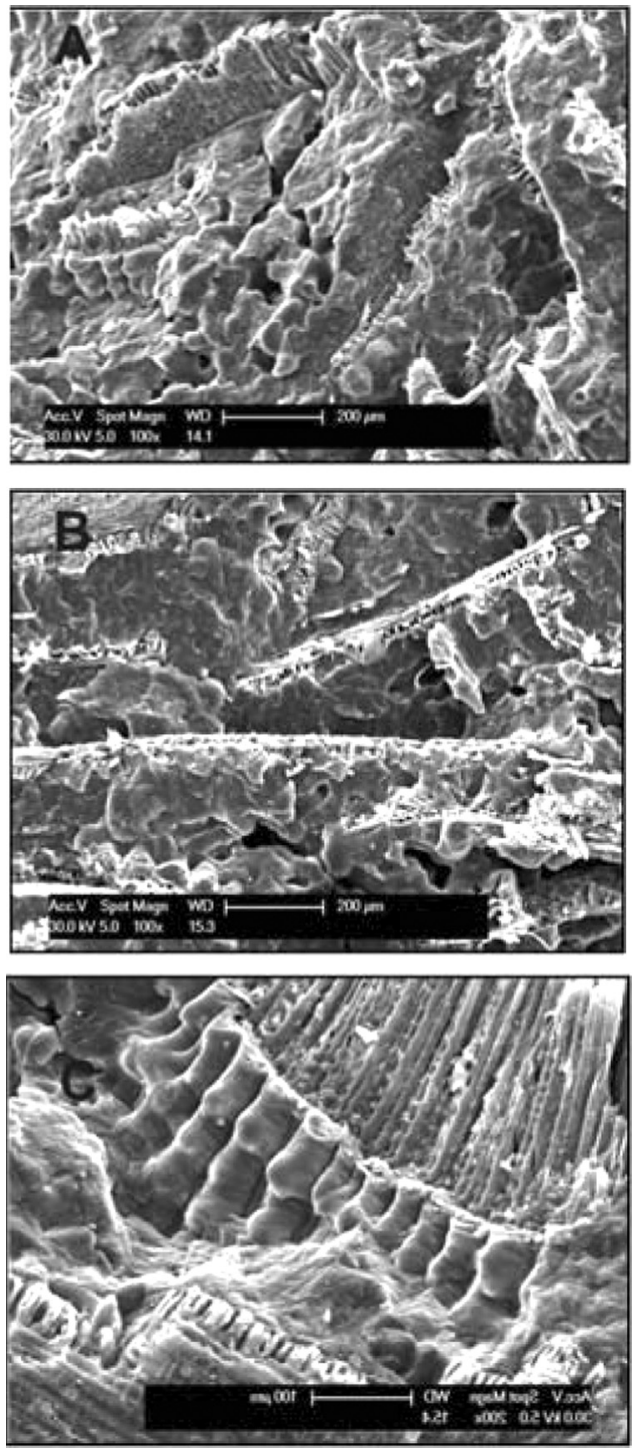

FIG. 7. SEM micrographs of cryogenically fractured surfaces of $P P / R H$ composite samples: $\mathrm{PP} / \mathrm{RH} / \mathrm{CA}$ composite (A), PPx1/RH/CA composite (B) and PPx2/RH/CA composite (C). 

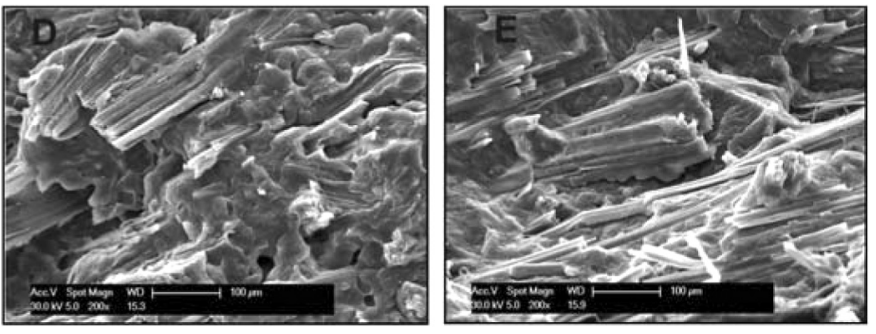

FIG. 8. SEM micrographs of cryogenically fractured surfaces of PP/ $\mathrm{K}$ composite samples: $\mathrm{PP} / \mathrm{K} / \mathrm{CA}$ composite (D) and $\mathrm{PPx} 1 / \mathrm{K} / \mathrm{CA}$ composite (E).

dispersion but also of the filler/matrix adhesion level after applying an external load.

For the PP/RH composites, the cellular structure of rice hulls embedded in the polymer matrix can be clearly observed, either for neat or for composites with recycled matrices. No significant differences were observed in the morphology of the composites with recycled matrices, thus indicating that further recycling of matrices does not induce relevant changes in the interfacial adhesion between rice hulls and matrix. These results are in agreement with the slight variations observed in mechanical properties and TGA results recorded for composites with recycled matrices.

In the case of $\mathrm{PP} / \mathrm{K}$ composites, unless kenaf fibres appear well embedded in the polymer matrix, some voids, evidence of typical debonding phenomena, can be observed as a result of cryogenic fracture, thus indicating a limited level of interfacial adhesion between matrix and fibers, especially for neat composite sample. The morphology of the composite samples seems slightly better for the composite with recycled matrix, for which an enhancement of the adhesion level between fibers and matrix is noted, thus confirming that recycling of the matrix can induce an improvement of compatibilization between matrix and fibers, in agreement with the results obtained through mechanical analysis and TGA.

\section{CONCLUSIONS}

Based on the results for the mechanical and thermal properties of $\mathrm{PP} /$ kenaf fiber and $\mathrm{PP} /$ rice hulls composites, in which recycled PP was used as a matrix, it was shown that it represents an effective material for production of eco-composites. Flexural strength of the composites produced from neat and recycled PP was similar, although a significant increase of flexural modulus was found for the recycled-PP kenaf fiber composites. Thermal stability of the recycled PP based composites is not changed significantly. SEM analyses have revealed that in the recycled PP-based composites, an even better effect of polymer/ fiber interactions is achieved. The obtained results for composite's flexural strength and modulus produced from the recycled PP based composites, both with kenaf fibers or rice hulls, are comparable to the conventional formaldehyde wood medium density fiberboards ${ }^{[17]}$.

\section{ACKNOWLEDGMENTS}

This work was supported by a grant of EU FP6-INCOWBC programme (INCO-CT-2004-509185). One of the authors (VS) appreciates the financial support for her research stay at the Institute of Chemistry and Technology on Polymers-ICTP - CRN, Naples, Italy.

\section{REFERENCES}

1. Yang, H.S.; Kim, D.J.; Kim, H.J. Bioresour. Technol. 2003, 86, 117.

2. Chen, Y.; Chiparus, L.S.; Negulescu, I.; Parikh, D.V.; Calamari, T.A. Natural fibers for automotive nonwoven composites. J. Ind. Text. 2005, 35 (1), 47-61.

3. Oksman, K.; Skrifvars, M.; Selin, J.F. Natural fibers as reinforcement in polylactic acid (PLA) composites. Compos. Sci. Technol. 2003, 63, 1317-1324.

4. Lee, S.H.; Wang, S. Biodegradable polymers/bamboo fiber biocomposite with bio-based coupling agent. Compos. Pt. A 2006, 37, 80-91.

5. Bogoeva-Gaceva, G.; Avella, M.; Malinconico, M.; Buzarovska, A.; Grozdanov, A.; Gentile, G.; Errico, M.E. Natural fiber ecocomposites. Polym. Compos. 2007, 28 (1), 98-107.

6. Avella, M.; Bonadies, E.; Martuscelli, E.; Rimedio, R. Polym. Test. 2001, 20, 517.

7. Mayer, J.M.; Kaplan, D.L. TRIP 1994, 7, 227.

8. Mieck, K.P.; Nechwatal, A.; Knobeldorf, C. Potential applications of natural fibres in composite materials. Melliand Textilberichte 1994, 11, 228-230 [in English].

9. Yang, H.S.; Kim, D.J.; Lee, J.K.; Kim, H.J.; Jeon, J.Y.; Kang, C.W. Possibility of using waste tire composites reinforced with rice straw as construction materials. Bioresource Technol. 2004b, 95, 61-65.

10. Mohanty, A.K.; Drzal, L.T.; Misra, M. J. Adhes. Sci. Technol. 2002, 16, 999.

11. Keener, T.J.; Stuart, R.K.; Brown, Y.K. Compos. A 2004, 35, 357.

12. Mohanty, A.K.; Misra, M.; Drzal, L.T. Compos. Interfaces 2001, 8, 313.

13. Bogoeva-Gaceva, G.; Grozdanov, A.; Buzarovska, A. Eco-friendly polymer composites based on polypropylene and kenaf fibers. Proceedings of 3rd International Conference on Eco Composites, Royal Institute of Technology, Stockholm, Sweden, June 20-21, 2005.

14. Nishino, T.; Arimoto, N. All-cellulose composites. Proceedings of $3 \mathrm{rd}$ International Conference on Eco-Composites, Royal Institute of technology, Stockholm, Sweden, June 20-21, 2005.

15. Toro, P.; Quijada, R.; Murillo, O.; Yazdani-Pedram, M. Study of the morphology and mechanical properties of polypropylene composites with silica or rice husk. Polym. Int. 2005, 54, 730-734.

16. ECO-PCCM, FP6-INCO-CT-2004-509185.

17. Serizawa, S.; Inoue, K.; Iji, M. Kenaf-fiber-reinforced poly(lactic acid) used for electronic products. J. Appl. Polym. Sci. 2006, 100, 618-624.

18. Yang, H.S.; Kim, H.J.; Son, J.; Park, H.J.; Lee, B.J.; Hwang, T.S. Compos. Struct. 2004, 63, 305.

19. Feng, D.; Caulfield, D.F.; Sanadi, A.R. Effect of compatibilizer on the structure-property relationships of kenaf-fiber/polypropylene composites. Polym. Compos. 2001, 22, 506-517.

20. Sanadi, A.R.; Caulfield, D.F.; Stark, N.M.; Clemons, C.C. Thermal and mechanical analysis of lignocellulosic-polypropylene composites. Proceedings of 5th Inter. Conf. on Wood Plastic Composites, Madison, Wisconsin, May 26-27: 67-78, 1999. 
21. Grozdanov, A.; Buzarovska, A.; Bogoeva-Gaceva, G.; Avella, M.; Errico, M.E.; Gentille, G. Rice straw as an alternative reinforcement in polypropylene composites. Agron. Sustain. Dev. 2006, 26, 251-255.

22. Kim, H.S.; Yang, H.S.; Kim, H.J.; Park, H.J. Thermogravimetric analysis of rice husk flour filled thermoplastic polymer composites. J. Therm. Anal. Calorim. 2004, 76, 395-404.

23. Trindade, W.G.; Hoareau, W.; Razera, I.A.T.; Ruggiero, R.; Frollini, E.; Castellan, A. Phenolic thermoset matrix reinforced with sugar cane baggase fibers; Attempt to develop a new fiber surface chemical modification involving formation of Quinones flowed by reaction with furfuryl alcohol. Macromol. Mater. Eng. 2004, 289, 728-736.

24. Ray, D.; Sarkar, B.K.; Basak, R.K.; Rana, A.K. Thermal behavior of vinyl ester resin matrix composites reinforced with alkali-treated jute fibers. J. Appl. Polim. Sci. 2004, 94, 123-139.

25. Canche-Escamilla, C.; Rodriguez-Trujillo, G.; Herrera-Franco, P.J.; Mendizabal, E.; Puig, J.E. Preparation and characterization of henequen cellulose grafted with methyl methacrylate and its application in composite. J. Appl. Polym. Sci. 1997, 66, 339-346. 